\title{
Rancang Bangun Sistem Informasi Lowongan Kerja Di JPC Polinema Dengan Metode Quick Sort
}

\author{
Budi Harijanto ${ }^{1}$, Deddy Kusbianto $\mathbf{P}^{2}$, Julia Intan Amini ${ }^{3}$ \\ Jurusan Teknologi Informasi, Program Studi Teknik Informatika, Politeknik Negeri Malang \\ budi.hijet@gmail.com¹,deddy_kusbianto@polinema.ac.id², juliaintan42@gmail.com³
}

\begin{abstract}
Abstrak
Informasi batas waktu lowongan kerja JPC di Facebook keberadaanya bertumpuk dengan informasi-informasi yang baru. Sehigga sulit untuk menemukan informasi lowongan kerja yang sudah melewati batas waktu dan informasi lowongan kerja yang sesuai dengan kriteria pelamar.Dari permasalahan tersebut maka dibuat aplikasi Lowongan Kerja Di JPC Polinema yang mampu menampilkan informasi lowongan kerja berdasarkan batas waktu dan kriteria pelamar. Metode yang digunakan untuk mensorting semua informasi lowongan kerja yang masuk menggunakan metode Quick Sort. Hasil dari penelitian ini akan menampilkan lowongan kerja setelah melalui sorting dengan batas waktu dan kriteria data pelamar. Kriteria ini terdiri dari 6 kriteria yang berupa gender, jurusan, jenjang, umur, IPK, dan pengalaman kerja.
\end{abstract}

Kata Kunci : Lowongan Kerja, Job Placement Center (JPC), Metode Quick Sort

1. Pendahuluan

\subsection{Latar Belakang}

Beberapa perusahaan besar maupun kecil di Indonesia menyediakan informasi lowongan kerja melalui media cetak maupun di papan pengumuman kerja serta melalui elektronik termasuk internet. Namun, diera globalisasi ini terdapatnya penyedia penyalur kerja untuk menampung lowongan pekerjaan dari perusahaan maupun instansi. Penyedia kerja ini biasanya dapat disebut dengan bursa kerja. Bursa kerja merupakan tempat bertemunya para perekrut kerja dengan para pencari kerja secara langsung dalam waktu yang singkat. Pada peguruan tinggi, bursa kerja umumnya digunakan untuk merekrut para alumi dan mahasiswa tingkat akhir. Salah satu kampus yang telah menjalin kerjasama dengan bursa tenaga kerja yakni Politeknik Negeri Malang (Polinema). Politeknik Negeri Malang berkerjasama dengan Job Placement Center (JPC).

JPC Polinema merupakan suatu lembaga atau wadah yang membantu Politeknik Negeri Malang (Polinema) dalam mengelola para alumi dan pencari kerja untuk menginformasikan lowongan kerja yang tersedia. JPC Pollinema diharapkan bisa membantu sebagai mediator antara para pencari kerja dengan perusahaan / instansi / industri yang sedang membuka lowongan kerja. Akan tetapi sistem kerja JPC Polinema saat ini masihlah semi manual, hal ini membuat calon pelamar merasa sedikit kesulitan.

Pada JPC Polinema informasi lowongan kerja, maupun pendaftaran untuk lamaran kerja memanfaatkan media sosial yakni fabcebook. Bila calon pelamar ingin mendaftarkan diri harus mengisikan nokta dikolom komentar di facebook pada lowongan kerja yang dipublikasikan. Selain itu untuk bergabung sebagai member calon anggota harus mendaftar dengan cara mengambil fomulir dan menyerahkan persyaratan lainnya di Kantor JPC Polinema. Tidak hanya itu, untuk melihat batas waktu terakhir pendaftaran pelamar harus melihat satu persatu postingan lowongan pekerjaan yang terpubliskasikan di facebook. Selain itu, sering kali ada calon pelamar yang tidak mengetahui batas waktu terakhir pendaftaran yang mengakibatkan pelamar tetap mendaftarkan diri di lowongan pekerjaan tersebut. Maka dari itu dibutuhkannya sebuah aplikasi yang dapat mengelolah batas waktu terakhir pendaftaran pekerjaan dengan tampilan yang selalu terupdate dan dapat menampilkan waktu yang mendekati masa terakhir pendaftaran lowongan pekerjaan secara terurut.

Salah satu metode yang mendukung pembuatan aplikasi ini adalah metode quick sort. Quick sort salah satu algoritma pengurutan data dengan menggunakan teknik membagi data menjadi partisi-partisi. Tahap awal untuk proses pengurutan data ini harus menentukan data yang dipilh sebagai data pivot kemudian dapat dilanjutkan untuk menentukan posisi data pivot.

Terhadap permasalahan diatas maka dibuatnya rancang bangun sistem informasi lowongan kerja di JPC Polinema dengan metode quick sort. Didalam sistem ini mencakup proses pendaftaran pelamar kerja dan member JPC Polinema, serta terdapatnya batas 
waktu terakhir pendaftaran lowongan pekerjaan secara terurut.

\subsection{Rumusan Masalah}

1. Bagaimana membuat sistem aplikasi untuk pelamar kerja agar dapat mendaftarkan diri ke lowongan kerja yang telah dipublikasikan oleh JPC Polinema?

2. Bagaimana membuat sistem aplikasi yang dapat menampilkan batas waktu terakhir pendaftaran lowongan pekerjaan dengan metode quick sort?

\subsection{Batasan Masalah}

Batasan masalah yang diberikan untuk merancang dan membangun aplikasi ini sebagai berikut :

1. Aplikasi yang akan dibuat memiliki dua user yakni pelamar kerja dan petugas pengelola data yang ada di JPC Polinema.

2. Pelamar kerja dapat mendaftar menjadi member di JPC Polinema serta dapat menggunakan nokta untuk melamar kerja yang dipublikasikan oleh JPC Polinema.

3. Data lowongan kerja dapat diurutkan sesuai batas waktu terakhir pendaftaran lowongan kerja.

\subsection{Tujuan}

Tujuan dalam penelitian ini sebagai berikut : Merancang dan membuat sistem aplikasi untuk pelamar kerja agar dapat mendaftarkan diri ke lowongan kerja yang telah dipublikasikan oleh JPC Polinema. Serta, dapat menampilkan batas waktu yang mendekati batas waktu terakhir pendaftaran lowongan pekerjaan.

\section{Kajian Pustaka \\ 2.1 Lowongan Kerja}

Lowongan Kerja atau kesempatan kerja adalah tersedianya lapangan kerja bagi angkatan kerja yang membutuhkan pekerjaan. Makasud dari angkatan kerja adalah penduduk dalam usia kerja (15 tahun ke atas), baik yang bekerja maupun yang tidak bekerja. Kesempatan kerja di Indonesia dijamin dalam Pasal 27 ayat 2 UUD 1945 yang berbunyi : "Tiap-tiap warga negara berhak atas pekerjaan dan penghidupan yang layak". Penjelasan dari pasal tersebut yakni bahwa pemerintah Indonesia bertanggung jawab atas penciptaan lapangan kerja.

\subsection{JPC Polinema}

Job Placement Center Polinema (JPC Polinema) merupakan media Politeknik Negeri Malang yang bertujuan menjembatani mahasiswa dan alumni Politeknik Negeri Malang dengan Dunia Usaha dan Dunia Industri (DUDI) dengan mengedepankan kecakapan dan keahlian sesuai yang dibutuhkan pasar kerja. JPC Polinema dibentuk berlandaskan Keputusan Direktur Politeknik Negeri Malang Nomor 6 Tahun 2013 tanggal 6 Pebruari 2013 serta berdasarkan Keputusan Direktur Politeknik Negeri Malang Nomor 106 Tahun 2013 tanggal 1 Juni 2013 mengangkat Drs. Bambang Soepeno, MMKom, MM sebagai Ketua Sekretariat Job Placement Center, dengan aktivitas utama :

1. Pemberian Pelatihan Mahasiswa untuk Persiapan Memasuki Dunia Kerja

2. Pemberian Pelatihan Alumni untuk Peningkatan Karir

3. Melaksanakan Progarm Magang untuk Mahasiwa untuk Jangka Pendek dan Jangka Panjang, maksimum 1 Tahun.

4. Melaksanakan Proses Penerimaan Tenaga Kerja bagi Dunia Usaha dan Dunia Industri (DUDI)

5. Melaksanakan Training Singkat Karyawan Dunia Usaha dan Dunia Industri (DUDI), maksimum 1 tahun dan bersertifikat Politeknik Negeri Malang.

6. Menyediakan Database Calon Tenaga Kerja Potensial untuk Dunia Usaha dan Dunia Industri (DUDI).

\subsection{Metode Quick Sort}

Metode Quick Sort diperkenalakan oleh C.A.R Hoare pada tahun 1960. Metodde pengurutan Quick Sort ini merupakan pengembangan lebih lanjut dari Shell Sort. Pengalaman dan perhitungan para ahli menunjukan bahwa Quick Sort ini merupakan metode yang sangat efisien dibandingkan metode pengurutan lainnya. Algoritma Quick Sort ini mengikuti langkahlangkah sebagai berikut :

1. Divide

Memilah rangkaian data menjadi dua subrangkaian $\mathrm{A}[\mathrm{p} . . . \mathrm{q}-1]$ dan

$\mathrm{A}[\mathrm{q}+1 \ldots \mathrm{r}]$ dimana setiap unsur $\mathrm{A}[\mathrm{p} \ldots \mathrm{q}-1]$ adalah kurang dari atau sama dengan $\mathrm{A}[\mathrm{q}]$ dan setiap unsur pada $\mathrm{A}[\mathrm{q}+1 \ldots \mathrm{r}]$ adalah lebih besar atau sama dengan unsur pada $\mathrm{A}[\mathrm{q}]$. $\mathrm{A}[\mathrm{q}]$ disebut sebagai unsur pivot. Perhitungan pada unsur q merupakan salah satu bagian dari prosedur pemisahan.

2. Conquer

Mengurutkan unsur pada subrangkaian secara rekursif Pada algoritma quicksort, langkah "kombinasi" tidak di lakukan karena telah terjadi pengurutan unsur - unsur pada sub-array. Quicksort termasuk pada pendekatan sulit membagi, mudah menggabung (hard split/easy join). Cara pemilihan pivot:

1) Pivot $=$ unsur pertama/unsur terakhir/unsur tengah tabel

2) Pivot dipilih secara acak dari salah satu unsur tabel. Pivot $=$ unsur median table 


\subsection{Processor Hypertext Protocol (PHP)}

PHP pertama kali ditemukan pada 1995 oleh seorang Software Developer bernama Rasmus Lerdrof. Ide awal PHP adalah ketika itu Rasmus ingin mengetahui jumlah pengunjung yang membaca resume onlinenya. Script yang dikembangkan baru dapat melakukan dua pekerjaan, yaitu merekam informasi visitor, dan menampilkan jumlah pengunjung dari suatu website. Dan sampai sekarang kedua tugas tersebut masih tetap populer digunakan oleh dunia web saat ini. Kemudian dari situ banyak orang di milis mendiskusikan script buatan Rasmus Lerdrof, hingga akhirnya rasmus mulai membuat sebuah tool/script, bernama PHP.

\subsection{Android}

Android merupakan sebuah sistem operasi telepon seluler dan komputer tablet layar sentuh (touch screen) yang berbasis linux. Namun seiring perkembangan, android berubah menjadi platform yang begitu cepat dalam melakukan inovasi. Hal ini tidak lepas dari pengembang utama dibelkangnya, yaitu google. Google-lah yang mengakusisi android, kemudian membuat sebuah platform. Platform Android terdiri dari sistem operasi berbasis Linux, sebuah GUI (Graphic User Interface), sebuah web browser dan Aplikasi End-User yang dapat di download dan juga para pengembang bisa dengan leluasa berkarya serta menciptakan aplikasi yang terbaik dan terbuka untuk digunakan oleh berbagai macam perangkat.

\section{Metode Penelitian}

Kompunen yang diperlukan untuk melakukan penelitian ini salah satunya adalah data. Data diperlukan sebagai objek pengujian rancang bangun sistem informasi lowongan kera di JPC Polinema dengan metode quick sort. Data yang akan diterapkan dimetode quick sort yakni data lowongan kerja yang memiliki batas waktu pendaftaran. Pada data yang dikelola akan menghasilkan urutan sesuai data lowongan kerja yang mendekati masa batas waktu pendaftran.

Pengumpulan data pada penelitian ini menggunakan metode survei. Adapun tahap pengumpulan data pada penelitian ini meliputi :

a. Wawancara

Merupakan suatu pengumpulan data dengan cara tanya jawab secara langsung terhadap pihak terkait. Pada penelitian ini melakukan wawancara kepada Kepala JPC Polinema. Dalam wawancara ini hal yang ditanyakan meliputi alur pendaftaran sebagai anggota member JPC polinema, prosedur pemberian informasi lowongan kerja terhadap calon pelamar, dan proses perekrutan kerja bila melalui lembaga JPC Polinema. b. Pengamataan Langsung

Pada pengamaatan langsung ini dilakukan supaya mengetahui alur saat ini yang sedang berjalan. Pengamatan langsung yang mendukung untuk penelitian ini dengan cara bergabung digrup JPC Polinema. Grup JPC Polinema ini memanfaatkan media sosial yakni facebook. Grup JPC Polinema bertujuan sebagai sarana informasi mengenai lowongan perkerjaan.

c. Studi Literatur

Studi literatur adalah mempelajari dan memhami konsep-konsep yang dibutukan untuk mengerjakan sistem. Sumber-sumber yang dapat dijadikan sebagai bahan Studi Pustaka adalah buku-buku karya pengarang terpercaya (lebih disarankan karya akademisi), jurnal-jurnal ilmiah dan hasil-hasil penelitian mahasiswa dalam berbagai bentuk misalnya skripsi, laporan, pratikum, dan sebagainya.

Proses desain akan dilakukan rancangan bangun sistem informasi lowongan kerja di JPC Polinema dengan metode Quick Sort . Proses ini berfokus pada struktur data sistem, proses dan representasi interface. Tahapan ini akan menghasilkan dokumen yang akan digunakan programmer untuk melakukan aktifitas pembuatan sistem. Untuk mengambarkan sistem dalam penelitian ini menggunakan data flow diagram (DFD). Berikut ini merupakan Data flow diagram yang akan ditunjukan pada Gambar 1 sebagai beikut :

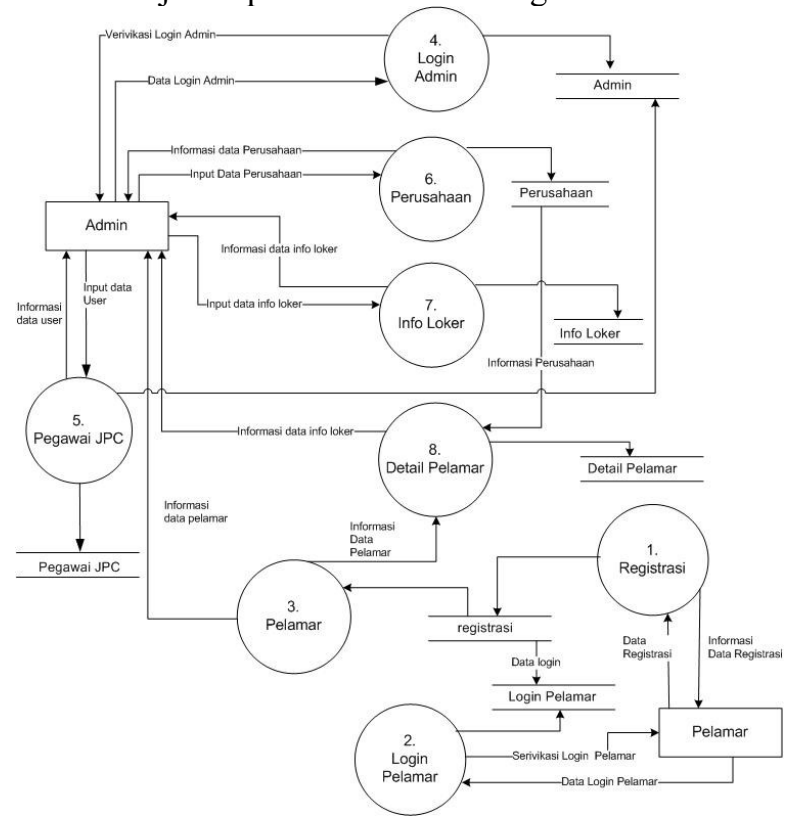

Gambar 1. DFD Level 1 
Pendefinisian secara detail DFD Level 1 sebagai beikut :

\begin{tabular}{|c|l|l|}
\hline No & \multicolumn{1}{|c|}{$\begin{array}{c}\text { Nama } \\
\text { Proses }\end{array}$} & \multicolumn{1}{c|}{ Deskripsi } \\
\hline 1. & $\begin{array}{l}\text { Login } \\
\text { Admin }\end{array}$ & $\begin{array}{l}\text { Proses untuk melakukan } \\
\text { login admin }\end{array}$ \\
\hline 2. & $\begin{array}{l}\text { Manajemen } \\
\text { data } \\
\text { Perusahaan }\end{array}$ & $\begin{array}{l}\text { Proses untuk melakukan } \\
\text { pengelolahan data perusahaan }\end{array}$ \\
\hline 3. & $\begin{array}{l}\text { Manajemen } \\
\text { Pegawai } \\
\text { JPC } \\
\text { Polinema }\end{array}$ & $\begin{array}{l}\text { Proses untuk melakukan } \\
\text { pengelolahan data hak akses } \\
\text { untuk melakukan } \\
\text { pengelolahan data pada } \\
\text { sistem. }\end{array}$ \\
\hline 4. & $\begin{array}{l}\text { Manajemen } \\
\text { data } \\
\text { infoloker }\end{array}$ & $\begin{array}{l}\text { Proses untuk melakukan } \\
\text { pengelolahan data infoloker }\end{array}$ \\
\hline 5. & $\begin{array}{l}\text { Manajemen } \\
\text { detail } \\
\text { pelamar }\end{array}$ & $\begin{array}{l}\text { Proses untuk memantau data } \\
\text { pelamar yang mendaftar } \\
\text { pekerjaan. }\end{array}$ \\
\hline 6. & $\begin{array}{l}\text { Manajemen } \\
\text { Registrasi }\end{array}$ & $\begin{array}{l}\text { Proses untuk melakukan } \\
\text { pendaftaran member pada } \\
\text { pelamar }\end{array}$ \\
\hline 7. & $\begin{array}{l}\text { Manajemen } \\
\text { Pelamar }\end{array}$ & $\begin{array}{l}\text { Proses untuk memantau data } \\
\text { pelamar atau member JPC } \\
\text { Polinema yang telah } \\
\text { melakukan regestrasi }\end{array}$ \\
\hline
\end{tabular}

\section{Hasil dan Pembahasan}

Bab ini membahas tentang implementasi sistem pada aplikasi yang menerapkan metode quick sort untuk mengurutkan data dari terkecil ke terbesar. Pembahasan implementasi ini terdiri implementasi database, sistem dan metode.

\subsection{Implementasi Database}

Berikut ini merupakan database pada implementasi sistem :

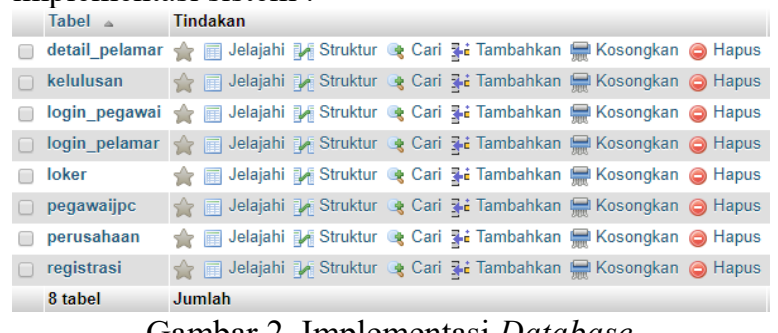

Gambar 2. Implementasi Database

\subsection{Implementasi Proses}

\subsubsection{Lihat Data Infoloker}

Berikut adalah halaman lihat data informasi lowongan kerja dilengkapi dengan tombol tambah infoloker. Pada disetiap data memiliki opsi edit dan hapus.

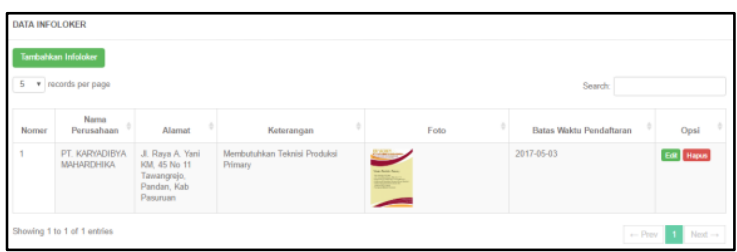

Gambar 3. Halaman Lihat Data Infoloker

\subsubsection{Lihat Data Loker Sesuai Batas Waktu}

Pada halaman ini merupakan tampilan data yang menggunakan metode quick sort dengan menyeleksi tanggal batas waktu pendaftaran. Pada halaman ini akan menampilakan lowongan kerja yang memiliki masa waktu yang belum melewati tanggal pada hari ini.

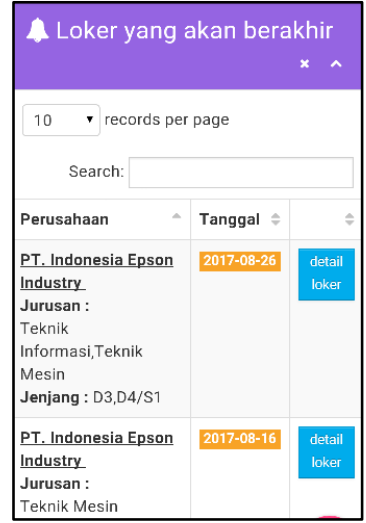

Gambar 4. Halaman Loker Sesuai Batas Waktu

4.2.2 Lihat Data Loker Sesuai Biodata Pelamar

Halaman ini merupakan halaman pembandingan data dari data perusahaan dengan biodata pelamar yang login. Sebelum melakukan pembadingan, data perusahan pada batas waktu diseleksi terlebih dahulu dengan tanggal saat ini . Kemudian diurutkan sesuai tanggal yang mendekati masa batas waktu pendaftaran dan dibandingkan lagi dengan kriteria yang telah ditentukan.

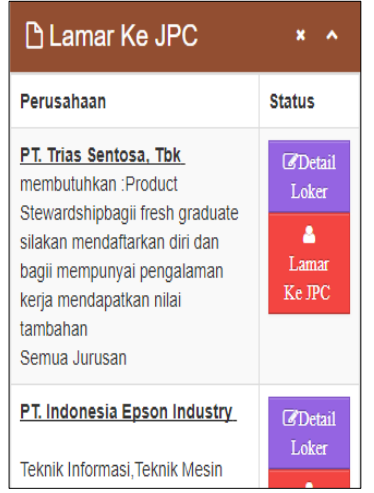

Gambar 5. Halaman Data Sesuai Biodata Pelamar 


\subsection{Pengujian Fungsional}

Berdasarkan hasil pengujian yang dilakukan, untuk pengujian secara fungsional yaitu dari setiap menu sudah berjalan dengan baik. Status uji dinyatakan berhasil setelah dilihat dari proses sistem pada pengujian. Hal ini ditunjukkan dengan kesesuaian dengan analisis dan rancangan yang telah dibahas pada tahap analisis dan perancangan.

\subsubsection{Pengujian Hasil Sistem Dengan Microsoft Excel}

Langkah pertama adalah menentukan tanggal hari ini dibandingkan dengan tanggal batas waktu pendaftaran, Berikut merupakan pengujian data dengan 10 data informasi lowongan kerja yang akan ditunjukan sebagai berikut :

Tabel 1, Urutan Data Sesuai Batas Loker

\begin{tabular}{|c|l|c|c|c|}
\hline \multicolumn{4}{|c|}{ Tanggal Hari ini : $2017-08-03$} & \multicolumn{3}{l|}{ Bentuk Integer : 20170803} \\
\hline \multicolumn{2}{|c|}{ Perbandingan tanggal hari ini dan batas waktu lowongan kerja } \\
\hline no & \multicolumn{1}{|c|}{ Nama Perusahaan } & Batas waktu & $\begin{array}{c}\text { Bentuk } \\
\text { Integer }\end{array}$ & hasil \\
\hline 1 & $\begin{array}{l}\text { PT. Asin Indonesia } \\
\text { Automotive }\end{array}$ & $2017-06-09$ & 20170609 & Nonaktif \\
\hline 2 & PT. CJ Feed Jombang & $2017-06-12$ & 20170612 & Nonaktif \\
\hline 3 & PT. Hasta Karya Perdana & $2017-07-03$ & 20170703 & Nonaktif \\
\hline 4 & PT. Hasta Karya Perdana & $2017-07-11$ & 20170711 & Nonaktif \\
\hline 5 & PT. Indonesia Epson Industry & $2017-08-16$ & 20170816 & aktif \\
\hline 6 & PT. Karyadibya Mahardhika & $2017-07-01$ & 20170701 & Nonaktif \\
\hline 7 & PT. Motasa Indonesia & $2017-07-23$ & 20170723 & Nonaktif \\
\hline 8 & PT. Indonesia Epson Industry & $2017-08-26$ & 20170826 & aktif \\
\hline 9 & PT. Trias Sentosa, Tbk & $2017-07-28$ & 20170728 & Nonaktif \\
\hline 10 & PT. Trias Sentosa, Tbk & $2017-08-25$ & 20170825 & aktif \\
\hline
\end{tabular}

Dapat disimpulkan data yang melewati batas waktu terdapat 7 data dengan hasil nonaktif. Sedangkan, data yang belum melewati batas waktu adalah data yang memiliki hasil aktif yang berada pada no 5,8,dan 10. Maka hasil pengurutan data dari terkecil ke data terbesar di excel sebagai berikut :

Tabel 2, Urutan Data Sesuai Batas Loker

\begin{tabular}{|l|l|l|}
\hline No & \multicolumn{1}{|c|}{ Perusahaan } & \multicolumn{1}{c|}{ Batas Waktu } \\
\hline 1 & PT. Indonesia Epson Industry & $2017-08-16$ \\
\hline 2 & PT. Trias Sentosa, Tbk & $2017-08-25$ \\
\hline 3 & PT. Indonesia Epson Industry & $2017-08-26$ \\
\hline
\end{tabular}

Kemudian hasil pada sistem yang telah dibuat akan ditunjukan pada Gambar 6 sebagai berikut :

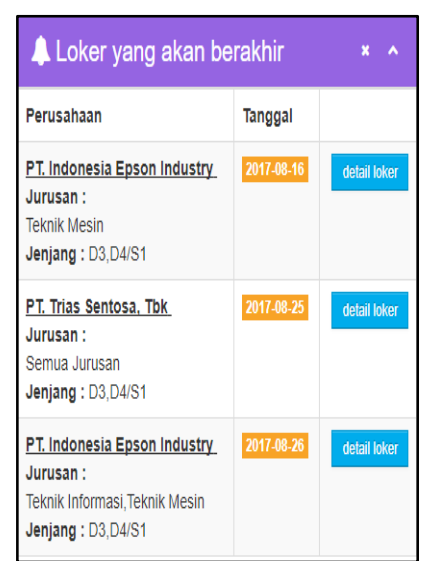

Gambar 6. Data Urut Dari Sistem

Hasil pada sistem menghasilkan data yang sama pada excel, maka pengurutan menggunakan metode quick sort untuk mengurutkan batas waktu loker telah berjalan dengan sesuai. Kemudian setelah data pengurutan tanggal dapat ditentukan maka data yang terpilih akan dibandingkan dengan kriteria antara data perusahaan dan biodata pelamar :

Keterangan Kriteria :

$$
\begin{array}{ll}
\mathrm{A}=\text { Gender } & \mathrm{D}=\text { Umur } \\
\mathrm{B}=\text { Jurusan } & \mathrm{E}=\mathrm{IPK} \\
\mathrm{C}=\text { Jenjang } & \mathrm{F}=\text { Pengalaman Kerja }
\end{array}
$$$$
\text { Maka perbandingan datanya menghasilkan: }
$$

Tabel 3, Hasil Data Pembanding Kriteria

\begin{tabular}{|l|l|l|l|l|}
\hline \multicolumn{2}{|c|}{ Data Pelamar } & Data Perusahaan 1 & Data Perusahaan 2 & Data Perusahaan 3 \\
\hline \multicolumn{2}{|l|}{ Agus Nugraha } & $\begin{array}{l}\text { PT. Indonesia Epson } \\
\text { Industry } \\
\text { Batas Waktu: } \\
\text { 2017-08-16 }\end{array}$ & $\begin{array}{l}\text { PT. Trias Sentosa, } \\
\text { Tbk } \\
\text { Batas Waktu: } \\
\text { 2017-08-25 }\end{array}$ & $\begin{array}{l}\text { PT. Indonesia Epson } \\
\text { Industry } \\
\text { Batas Waktu: } \\
\text { 2017-08-26 }\end{array}$ \\
\hline A & Pria & Cocok & Cocok & Cocok \\
\hline B & Teknik Mesin & Cocok & Cocok & Cocok \\
\hline C & D4 & Cocok & Cocok & Cocok \\
\hline D & 23 & Cocok & Cocok & Cocok \\
\hline E & 3.75 & Cocok & Cocok & Cocok \\
\hline F & 0 & Tidak Cocok & Cocok & Cocok \\
\hline
\end{tabular}

Pada hasil perbandingan diatas data perusahaan 1 pada PT. Indonesia Epson Industry tidak cocok dengan data pelamar karena pada perusahaan tersebut memiliki persyaratan pengalaman kerja 1 tahun. Sedangkan data pelamar mempunyai data pengalaman kerja nol atau tidak ada pengalaman kerja. Sedangkan, data perusahaan 1 dan data perusahan 2 memiliki persyaratan kerja yang sesuai dengan biodata pelamar. Maka data perusahaan yang dapat dilamar oleh pelamar yakni PT. Trias Sentosa, Tbk dan PT. Indonesia Epson Industry. Untuk hasil pada sistem data yang dihasilkan antar data perusahaan dan biodata pelamar akan ditunjukan pada Gambar 4.6 sebagai berikut: 


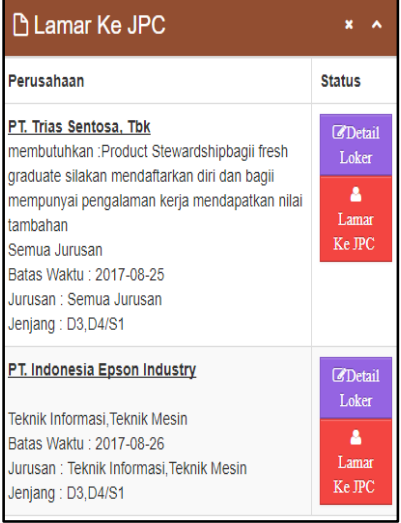

Gambar 7. Data Pembanding Didistem

Hasil dari data pada sistem menunjukan hasil yang sama pada perbandingan di Excel maka dari itu sistem yang dibuatdapat dilakukan perhitungan akurasi sebagai berikut.

Data yang dicoba terdapat 10 Lowongan pekerjaan dan data yang sesuai sebanyak 10 data dan data yang tidak sesuai tidak ada, maka perhitungan akurasi :

Akurasi (\%) $=\frac{\text { Banyak data cocok }}{\text { Jumlah data keseluruhan }} \times 100 \%$

Akurasi (\%) $=\frac{10}{10} \times 100 \%=100 \%$ (1)

Hasil akurasi yang didapat antar pecobaan di excel dan sistem mencapai nilai akurasi $100 \%$.

\section{Kesimpulan}

Dari pembahasan yang dijelaskan pada bab 1 sampai 6 dapat diperoleh beberapa kesimpulan sebagai berikut :

1. Sistem informasi lowongan kerja Kerja Di JPC Polinema Dengan Metode Quick Sort dapat digunakan dengan mudah oleh pengguna atau anggota JPC Polinema (Pelamar).

2. Sistem Informasi Lowongan Kerja Di JPC Polinema Dengan Metode Quick Sort mempermudah pelamar dalam melakukan registrasi anggota JPC Polinema. Serta, mempermudah pelamar dalam mendapatkan informasi lowongan kerja.

3. Sistem Informasi Lowongan Kerja Di JPC Polinema Dengan Metode Quick Sort dapat digunakan pelamar untuk melamar lowongan kerja yang telah di publikasikan ke JPC Polinema.

4. Dalam Rancang Bangun Sistem Informasi Lowongan Kerja Di JPC Polinema Dengan Metode Quick Sort dapat menampilkan data yang terurut sesuai batas waktu yang mendekati masa akhir pendaftaran pada lowongan kerja dan sesuai biodata pelamar kerja.

\section{Daftar Pustaka}

Android Kasman,D.A.2016.Trik Kolaborasi ANDROID dengan PHP dan MYSQL. Yogyakarta : Penerbit Lokomedia.

Nugroho,A.2008. Algoritma dan Struktur Data dalam Bahasa Java. Yogyakarta: Penerbit Andi

Polinema.2013,JPC. Available: http://www.polinema.ac.id/kerjasama/jpc/ Di akses 07 Januari 2017

S, Alam. 2007. Ekonomi untuk SMA dan MA Kelas XI KTSP Standar Isi 2006. Jakarta : Penerbit Erlangga.

Sidik, B. 2006. Pemrograman Web dengan PHP. Bandung: Penerbit Informatika. 